\title{
Substrate stiffness influences TGF- $\beta 1$-induced differentiation of bronchial fibroblasts into myofibroblasts in airway remodeling
}

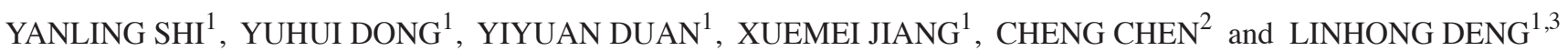 \\ ${ }^{1}$ Key Laboratory of Biorheological Science and Technology, Ministry of Education and \\ Bioengineering College, Chongqing University, Chongqing 400044; ${ }^{2}$ Center for Joint Surgery, Southwest Hospital, \\ The Third Military Medical University, Chongqing 400038; ${ }^{3}$ Institute of Biomedical Engineering \\ and Health Sciences, Changzhou University, Changzhou, Jiangsu 213164, P.R. China
}

Received August 30, 2012; Accepted November 13, 2012

DOI: $10.3892 / \mathrm{mmr} .2012 .1213$

\begin{abstract}
Chronic inflammation and remodeling of the bronchial wall are basic hallmarks of asthma. During the process of bronchial wall remodeling, inflammatory factors, such as transforming growth factor- $\beta 1$ (TGF- $\beta 1$ ), are known to induce the differentiation of fibroblasts into myofibroblasts, which leads to excessive synthesis and secretion of extracellular matrix (ECM) proteins, thus thickening and stiffening the basement membrane. However, it has not been thoroughly studied whether or not substrate stiffening affects the TGF- $\beta 1$-induced myofibroblast differentiation. In the present study, the influence of substrate stiffness on the process of bronchial fibroblast differentiation into myofibroblasts in the presence of TGF- $\beta 1$ was investigated. To address this question, we synthesized polydimethylsiloxane (PDMS) substrates with varying degrees of stiffness (Young's modulus of 1, 10 and $50 \mathrm{kPa}$, respectively). We cultured bronchial fibroblasts on the substrates of varying stiffness in media containing TGF- $\beta 1(10 \mathrm{ng} / \mathrm{ml})$ to stimulate the differentiation of fibroblasts into myofibroblasts. Myofibroblast differentiation was examined using semi-quantitative RT-PCR for the expression of $\alpha$-smooth muscle actin ( $\alpha$-SMA) mRNA and collagen I mRNA, the enzyme-linked immunosorbent assay method was used to assess the expression of collagen I protein and western blotting to assess the expression of $\alpha$-SMA protein. The optical magnetic twisting cytometry (OMTC) method was used for the changing of cell mechanical properties. Our findings suggest that when fibroblasts were incubated with TGF- $\beta 1(10 \mathrm{ng} / \mathrm{ml})$ on substrate of varying stiffness, the differentiation of fibroblasts into myofibroblasts was enhanced by increasing substrate stiffness. Compared with those cultured
\end{abstract}

Correspondence to: Dr Linhong Deng, Institute of Biomedical Engineering and Health Sciences, Changzhou University, 1 Gehu Street, Changzhou, Jiangsu 213164, P.R. China

E-mail:dlh@cczu.edu.cn

Key words: asthma, substrate stiffness, airway wall remodeling, fibroblasts, differentiation, transforming growth factor- $\beta 1$ on substrate with Young's modulus of $1 \mathrm{kPa}$, the mRNA and protein expression of collagen I and $\alpha$-SMA of fibroblasts cultured on substrates with Young's modulus of 10 and $50 \mathrm{kPa}$ were increased. Furthermore, with the increase of substrate stiffness, the cell stiffness and contractility were also increased, which also indicated further aggravation of asthma. This finding may help better understand the underlying mechanisms of hyperplasia of myofibroblasts in asthma, which has a marked significance in the therapy of asthma.

\section{Introduction}

Asthma is characterized by airway inflammation, hyperresponsiveness and remodeling. During the process of airway remodeling, airway wall thickening, subepithelial fibrosis, mucous metaplasia, myocyte hyperplasia and hypertrophy and myofibroblast hyperplasia occur (1-4).

The myofibroblast is often described as possessing a phenotype between that of a fibroblast and a smooth muscle cell, while the presence of $\alpha$-smooth muscle actin ( $\alpha$-SMA) has been considered a marker of myofibroblast differentiation (5). The myofibroblast may be generated from fibroblasts. Although several factors are able to induce the differentiation of fibroblasts into myofibroblasts (6), the most potent inducer in vitro is transforming growth factor- $\beta 1$ (TGF- $\beta 1)$ (7-9). This profibrogenic growth factor is increased in asthma and has been associated with myofibroblast proliferation and airway remodeling (10). In particular, the TGF- $\beta 1$ isoform has been implicated in the pathogenesis of asthma due to its release from damaged epithelial cells and myofibroblasts, which is an important morbigenous factor in the process of airway remodeling. Myofibroblasts are major producers of collagenous and noncollagenous matrix molecules, thus thickening and stiffening the basement membrane. These features of the myofibroblast may play an important role in asthma $(11,12)$.

Mechanical forces are highly involved in fundamental cell processes including mechanotransduction, growth, differentiation, protein and DNA synthesis, motility and apoptosis (13-16). During recent years, there has been a growing appreciation of the profound effects that passive mechanical properties, such 
as viscosity (17), microstructure (18) and especially stiffness (19-22) of the local environment, may have on cellular functions relevant to development, homeostasis and disease.

In view of the thickening and stiffening of the basement membrane in asthma, it has not been well studied whether substrate stiffening affects the TGF- $\beta 1$-induced myofibroblast differentiation. This paucity of knowledge has motivated us to investigate the influence of substrate stiffness on the process of bronchial fibroblast differentiation into myofibroblast in the presence of TGF- $\beta 1$.

\section{Materials and methods}

Materials. Substrates with varying degrees of stiffness were made of polydimethylsiloxane (PDMS, Sylgard 184; Dow Corning, Midland, MI, USA). The synthetic arginine-glycineaspartic acid (RGD)-containing peptide was purchased from American Peptide Company (Sunnyvale, CA, USA). The ferrimagnetic beads (diameter $4.5 \mu \mathrm{m}$ ) were kindly provided by Dr J.J. Fredberg of Harvard School of Public Health (Cambridge, MA, USA). Unless otherwise noted, all other reagents were purchased from Fisher Scientific (Newark, DE, USA). The study was approved by the ethics committee of Bioengineering College, Chongqing University, Chongqing, China.

PDMS substrates and stiffness (Young's modulus) measurements. PDMS is a widely-used bio-compatible substrate for cell behavior studies (23-25). The PDMS stiffness may be controlled by the cross-linker agent concentration (CLC) in the PDMS solution, the temperature and the time of baking (26). We prepared the substrates with varying stiffness (Young's modulus of 1, 10 and $50 \mathrm{kPa}$, respectively).

First, the PDMS samples were prepared with the ratio of CLC in PDMS solution of 0.012,0.014, 0.020,0.025 and 0.030 in 35-mm Petri dishes (Greiner Bio-One, Frickenhausen, Germany) and baked at a constant temperature of $60^{\circ} \mathrm{C}$ (normal pressure conditions) for 3 days. Then, the cured PDMS gel was measured for its stiffness, i.e., the Young's modulus (kPa), using a rotational rheometer (Gemni HR rheometer, Malvern, $\mathrm{UK})$ at 5 different frequencies $(0.01,0.10,1.00,10.00$ and $30.00 \mathrm{~Hz})$. Secondly, the cross-linker concentration required to fabricate the PDMS gel with the given Young's modulus (1, 10, $50 \mathrm{kPa}$ ) was determined from the above measured relationship between the PDMS's Young's modulus $(\mathrm{kPa})$ and the crosslinker concentration (CLC).

Cell culture and immunohistochemical staining. Bronchial fibroblasts obtained from Sprague-Dawley (SD) rats were grown. Primary fibroblast cultures were established as previously described (27). Fibroblasts were cultured using Dulbecco's modified Eagle medium (DMEM) (BioWhittaker, Walkersville, MD, USA) supplemented with $10 \%$ fetal bovine serum (FBS), $100 \mathrm{U} / \mathrm{ml}$ penicillin and $100 \mathrm{U} / \mathrm{ml}$ streptomycin (Gibco-BRL, Carlsbad, CA, USA). Cultures were passaged weekly at a 1:3 split ratio and were used between passages 2 and 7 .

Following plating for $24 \mathrm{~h}$, cells were fixed with $4 \%$ paraformaldehyde (Sigma-Aldrich, St. Louis, MO, USA) at $37^{\circ} \mathrm{C}$ for $30 \mathrm{~min}$. The samples were blocked and permeabilized with $1 \%$ bovine serum albumin (Sigma-Aldrich) and $0.2 \%$ Triton (Sigma-Aldrich) for $30 \mathrm{~min}$. Cells were then incubated with
Table I. PCR primer pairs.

\begin{tabular}{lc}
\hline Isoform & Primer sequences \\
\hline$\alpha-S M A$ & \\
Forward & 5'-CTTCTATAACGAGCTTCGC-3' \\
Reverse & 5'-TCCAGAGTCCAGCACAAT-3' \\
Collagen I & \\
Forward & 5'-CGAGTATGGAAGCGAAGGTT-3' \\
Reverse & 5'-CATCCACAAGCGTGCTGTAG-3' \\
$\beta$-actin & \\
Forward & 5'-CTGCCGCATCCTCTTCCTC-3' \\
Reverse & 5'-CTCCTGCTTGCTGACCACAT-3'
\end{tabular}

anti-vimentin antibody (1:400; Boster, Wuhan, China) and anti- $\alpha$-SMA antibody (1:300; Boster), respectively. Following incubation, the cells were washed twice in PBS and further incubated with a horseradish peroxidase-conjugated goat anti-mouse IgG (1:3,000; Boster). Specimens were visualized under a microscope and photographed. The cells were positive for vimentin, while $1 \%$ of the cells were $\alpha$-SMA-positive in the absence of TGF- $\beta 1$.

Cell culture on substrates of varying stiffness. The PDMS substrates were coated with fibronectin $(10 \mu \mathrm{g} / \mathrm{ml}$; Sigma-Aldrich) overnight for cell culture. Bronchial fibroblasts were seeded onto substrates with varying stiffness (Young's modulus of 1,10 and $50 \mathrm{kPa}$, respectively) and grown to $80-95 \%$ confluence prior to serum (Sijiqing Biological Engineering Materials Company, Hangzhou, China) starvation for $24 \mathrm{~h}$ followed by treatment with TGF- $\beta 1$ (10 ng/ml; Sigma, Poole, UK) for $48 \mathrm{~h}$ to stimulate the differentiation of fibroblasts into myofibroblasts.

$R N A$ isolation and semi-quantitative reverse transcriptase polymerase chain reaction ( $q$ RT-PCR). Total ribonucleic acid (RNA) was extracted and treated with RNase-free DNase to eliminate contamination. cDNA synthesis was performed by reverse transcription with oligo(dT) primers (Takara Bio, Shiga, Japan) and Superscript II Reverse Transcriptase (Takara Bio). Specific cDNAs for $\alpha$-SMA and collagen I and $\beta$-actin isoforms were amplified with primer pairs (Table I) by PCR for 26 cycles: denaturing at $94^{\circ} \mathrm{C}$ for $30 \mathrm{sec}$, annealing at $61.2^{\circ} \mathrm{C}$ for $1 \mathrm{~min}$ and a final extension at $72^{\circ} \mathrm{C}$ for $30 \mathrm{sec}$. Specific, forward and reverse primers spanning a 202-bp fragment encoding $\alpha$-SMA, a 233-bp fragment of collagen I and a 396-bp fragment of $\beta$-actin cDNAs were used. The primer pairs yielded the appropriate sizes of RT-PCR products, were separated on $1.5 \%$ agarose gels, digitally photographed and the intensity of the bands was quantified in correlation with the $\beta$-actin band and values expressed as a ratio to the controls.

Enzyme-linked immunosorbent assay (ELISA). After the cells were cultured on substrates with varying degrees of stiffness and treated with TGF- $\beta 1(10 \mathrm{ng} / \mathrm{ml})$ for $48 \mathrm{~h}$, the supernatant was collected. The collagen I in the supernatant was detected using a Rat collagen Type I, Col I ELISA kit (Senxiong Biotech, Shanghai, China). 

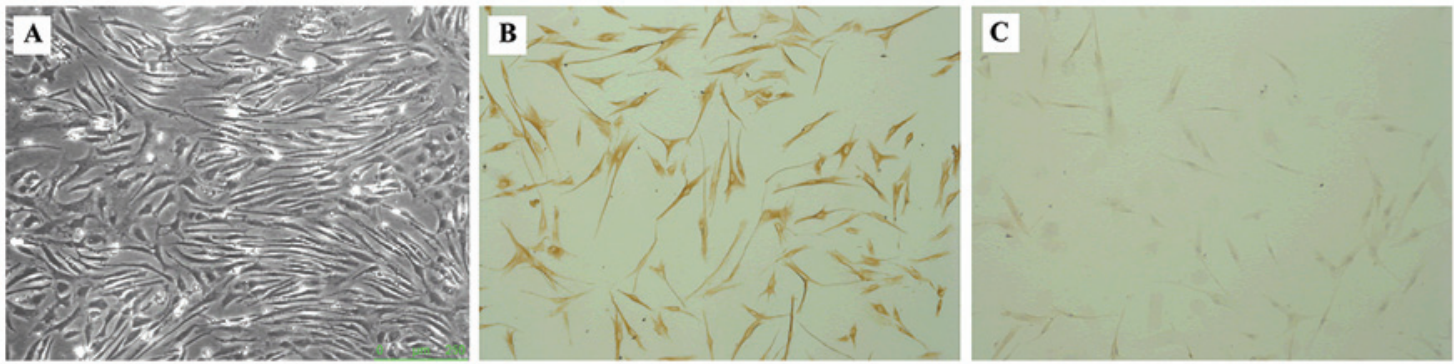

Figure 1. Characterization of bronchial fibroblasts. (A) Cultured bronchial fibroblasts displayed a characteristic 'fusiform' appearance (original magnification, $\mathrm{x} 10$, phase contrast microscope); (B) Positive expression of vimentin in bronchial fibroblasts (immunocytochemistry). Bar, $50 \mu$ m; (C) Negative expression of $\alpha$-SMA in bronchial fibroblasts (immunocytochemistry). Bar, $50 \mu \mathrm{m}$.

Western blotting. Total proteins were prepared by adding $500 \mu \mathrm{l}$ lysis buffer. Plates were incubated at $4^{\circ} \mathrm{C}$ for $30 \mathrm{~min}$, scraped and the protein concentration determined with a Bio-Rad protein assay kit (Bio-Rad, Hercules, CA, USA). Total protein $(25 \mu \mathrm{g})$ in each lane was separated using the sodium dodecyl sulfate polyacrylamide gel electrophoresis (SDS-PAGE) method on $12.5 \%$ acrylamide precast gels. The electrophoresed proteins were transferred to a nitrocellulose membrane. Subsequent to blocking with 3\% BSA, a panel of monoclonal antibodies against $\alpha$-SMA (1:300; Boster) were applied. Signals were visualized using a horseradish peroxidase-conjugated goat anti-mouse $\operatorname{IgG}(1: 3,000$; Boster) and enhanced chemiluminescent reagent (ECL; Amersham-Pharmacia Biotech, UK) and were quantified on autoradiographs that depicted bands within a linear range of exposures.

Measuring cell mechanical properties. Mechanical properties of cells on substrates of varying stiffness were assessed by optical magnetic twisting cytometry (OMTC), of which the details have been thoroughly described in previous studies $(28,29)$. Bronchial fibroblasts were seeded onto 96 -well plates with varying stiffness (Young's modulus of 1, 10 and $50 \mathrm{kPa}$, respectively). Cells were cultured as described above. Subsequently, detection of the cell stiffness and cell contractility in response to stimulation by potassium chloride $(\mathrm{KCl})$, was performed by OMTC, respectively.

Statistical analyses. The results are presented as the means \pm standard error (SE) and analyzed using OriginPro software (version 6.1). To assess the differences between conditions the Student's t-test for unpaired data was used. $\mathrm{P}<0.05$ was considered to indicate a statistically significant difference, and $\mathrm{P}<0.01$ an extremely significant difference.

\section{Results}

Characterization of bronchial fibroblasts. Primary bronchial fibroblasts were cultured for this experiment and reached confluence in 3-4 weeks. Confluent bronchial fibroblasts gave a characteristic 'fusiform' appearance. Immunocytochemical staining of rat bronchial fibroblasts was performed with antibodies against $\alpha$-SMA (1:300; Boster) and antibodies against vimentin (1:400; Boster). Typically, all cells were positive for vimentin, while $1 \%$ of the cells were $\alpha$-SMA-positive (Fig. 1).

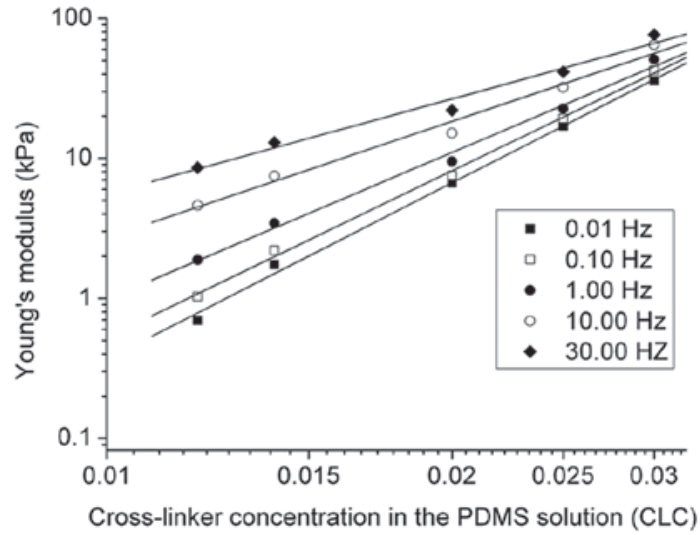

Figure 2. Young's modulus measurements of polydimethylsiloxane (PDMS) substrates. Cross-linker concentration (CLC) of 0.012, 0.014, 0.020, 0.025 and 0.030 , respectively, in the PDMS solution produced the required PDMS stiffness $(\mathrm{kPa})$. The Young's modulus of every matching was detected in 5 frequencies $(0.01,0.10,1.00,10.00$ and $30.00 \mathrm{~Hz})$.

PDMS Young's modulus measurements. Fig. 2 shows the results of Young's modulus measurements of PDMS substrates using a rheometer. In all cases, the Young's modulus of PDMS substrates exhibited typical power-law behavior whereby Young's modulus $(\mathrm{kPa})$ increased with the concentration of cross-linker in the PDMS solution, as shown in Fig. 2. In this study, we selected the PDMS Young's modulus measured at the lowest frequency $(0.01 \mathrm{~Hz})$ to be representative of the relationship between the PDMS stiffness and the cross-linker agent concentration (CLS). The least square curve fitting of the measured PDMS Young's modulus versus CLS in log-log scale indicates a linear relationship as follows: Log (Young's modulus $)=3.986 \log ($ CLC $)+7.536$ eq.(1) .

From this equation, we determined the concentration of cross-linker agent required to achieve the corresponding Young's modulus of PDMS at 1, 10,50 kPa, was $0.013,0.023$, and 0.034 , respectively. Thus, all the PDMS substrates used for experiments throughout this study were prepared according to these CLS concentrations

Effect of substrate stiffness on expression of $\alpha$-SMA and collagen I $m R N A$. To examine whether $\alpha$-SMA mRNA and collagen I mRNA of myofibroblast expression is regulated by substrate stiffness, we performed sqRT-PCR on cDNA templates derived from cells cultured on substrates with varying degrees of stiffness (Young's modulus of 1, 10 and 

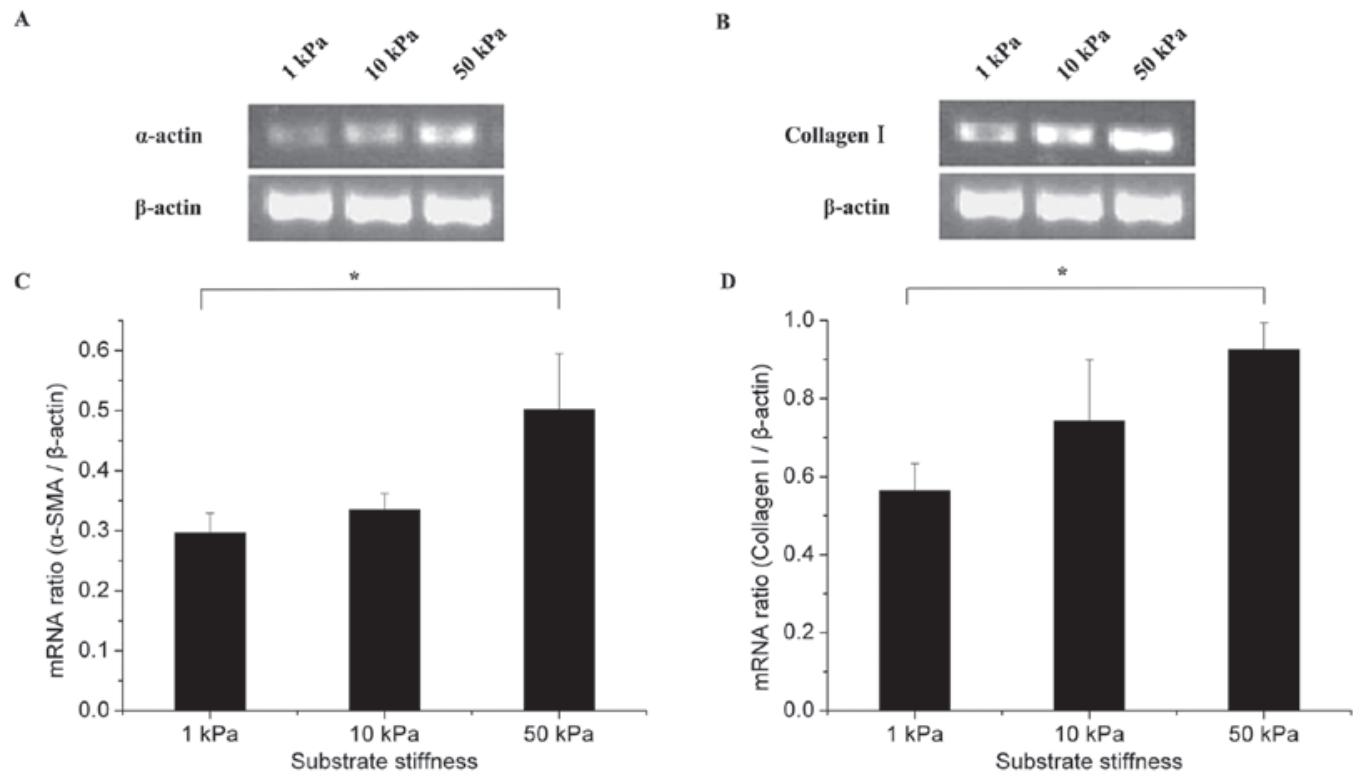

Figure 3. Effect of substrate stiffness on expression of $\alpha$-SMA and Collagen I mRNA. Expression of (A) $\alpha$-SMA mRNA and (B) collagen I mRNA. Results are expressed as the ratios of (C) $\alpha$-SMA to $\beta$-actin and (D) collagen I to $\beta$-actin analyzed respectively from three separate experiments. ${ }^{*} \mathrm{P}<0.05$.

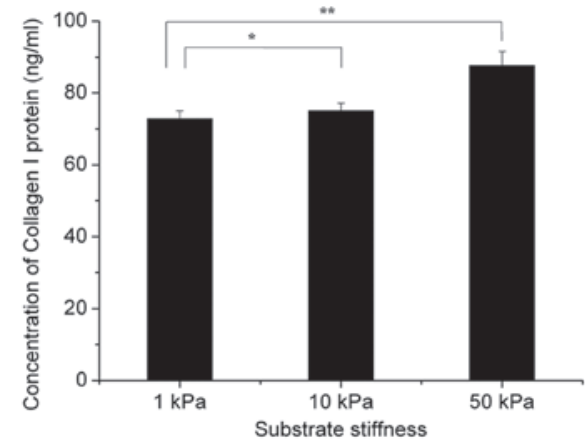

Figure 4. Effect of substrate stiffness on expression of collagen I protein. Serum-starved, bronchial fibroblasts were cultured on substrates with stiffness of 1,10 and $50 \mathrm{kPa}$ and treated with TGF- $\beta 1(10 \mathrm{ng} / \mathrm{ml})$ for $48 \mathrm{~h}$. Expression of collagen I protein was detected using the ELISA method. ${ }^{*} \mathrm{P}<0.05,{ }^{* *} \mathrm{P}<0.01$.

$50 \mathrm{kPa}$, respectively). Fig. 3A and B shows a representative image following agarose gel electrophoresis with PCR products for $\alpha$-SMA (202 bp), collagen I (233 bp) and $\beta$-actin (396 bp). The bands were analyzed using the appropriate image analysis software. $\alpha$-SMA $/ \beta$-actin (Fig. $3 \mathrm{C}$ ) and collagen I/ $\beta$-actin (Fig. 3D) values were assessed, respectively. When fibroblasts were incubated with TGF- $\beta 1(10 \mathrm{ng} / \mathrm{ml})$ on substrate of varying stiffness, the $\alpha$-SMA and collagen I mRNA expression of cells cultured on substrates with Young's modulus at $10 \mathrm{kPa}$ increased 0.14 - and 0.32 -fold, respectively, compared with those at $1 \mathrm{kPa}$. However, for the cells cultured on substrates with Young's modulus at $50 \mathrm{kPa}$, the increases were 0.72 - $(\mathrm{P}<0.05)$ and 0.64 -fold $(\mathrm{P}<0.05)$, respectively.

Effect of substrate stiffness on expression of collagen I protein. An ELISA kit was used to assess the effect of substrate stiffness on expression of collagen I protein, following treatment with TGF- $\beta 1$ for $48 \mathrm{~h}$. Collagen I protein expression of cells cultured on substrates with Young's modulus of $10 \mathrm{kPa}$ increased 0.03fold $(\mathrm{P}<0.05)$ compared with those with Young's modulus of

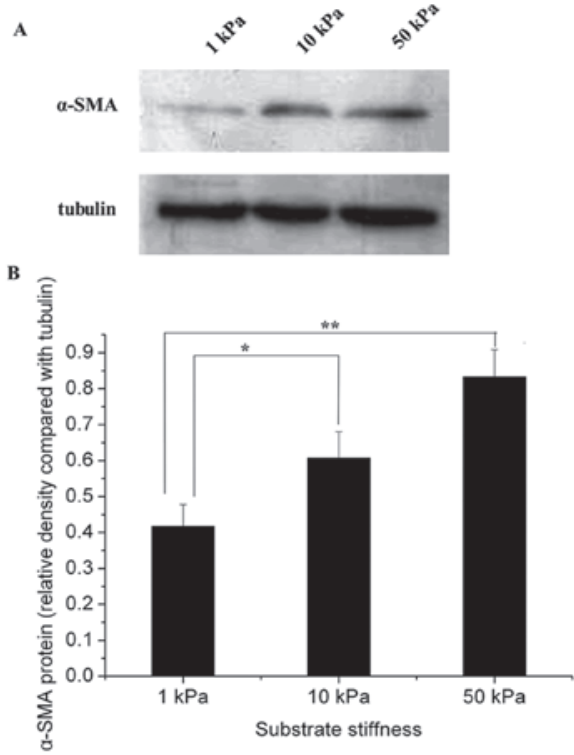

Figure 5. Effect of substrate stiffness on expression of $\alpha$-SMA protein. The form of $\alpha$-SMA protein was detected using western blot analysis. (A) Expression of $\alpha$-SMA protein. (B) Results are expressed as the relative density of $\alpha$-SMA compared with tubulin analyzed from three separate experiments. ${ }^{*} \mathrm{P}<0.05,{ }^{* *} \mathrm{P}<0.01$.

$1 \mathrm{kPa}$, whereas for the cells cultured on substrates with Young's modulus at $50 \mathrm{kPa}$, the increases were 0.2 -fold $(\mathrm{P}<0.01)$ (Fig. 4).

Effect of substrate stiffness on expression of $\alpha$-SMA protein. To investigate the biochemical contractile phenotypic changes after fibroblasts were cultured on substrates with varying stiffness and treated with TGF- $\beta 1$ for $48 \mathrm{~h}$, the expression of $\alpha$-SMA protein was examined using western blot analyses. A $0.43-(\mathrm{P}<0.05)$ and a 1.02-fold $(\mathrm{P}<0.01)$ increase was observed in $\alpha$-SMA protein expression of cells cultured on substrates with Young's modulus of 10 and $50 \mathrm{kPa}$, respectively, compared with those with Young's modulus of $1 \mathrm{kPa}$ (Fig. 5). 


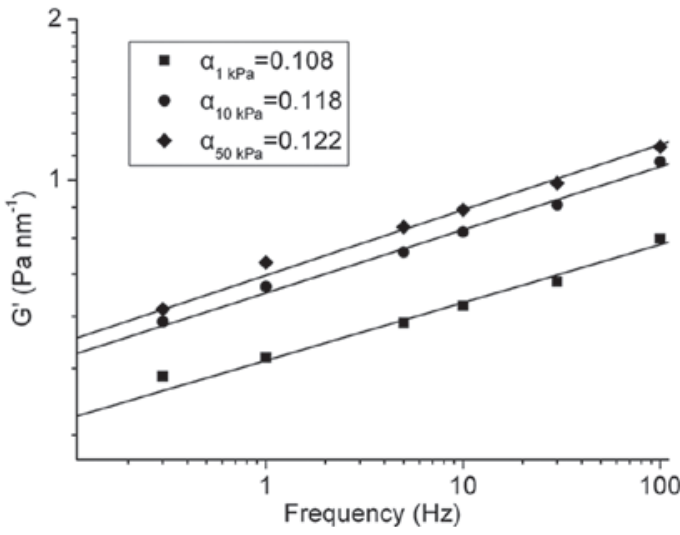

Figure 6. The stiffness, G' (Pa nm-1), of TGF- $\beta 1$-induced fibroblasts cultured on substrates with stiffness of 1,10 and $50 \mathrm{kPa}$, measured by optical magnetic twisting cytometry (OMTC). Power-law relationships were fitted to the results shown as the straight lines, and the slopes of the power-law correlations for each condition are shown in the box.
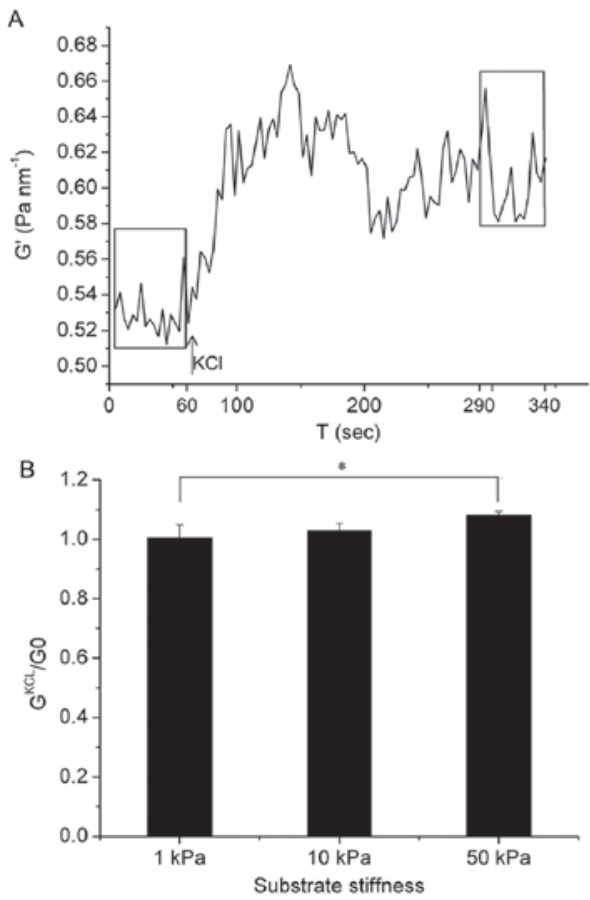

Figure 7. (A) Representative recording of the time course of cell stiffness measured by optical magnetic twisting cytometry (OMTC) prior and subsequent to $80 \mathrm{mM} \mathrm{KCl}$ administration. The stiffness measured prior to $\mathrm{KCl}$ administration was averaged to represent the baseline stiffness (G0) and the plateau stiffness subsequent to $\mathrm{KCl}$ administration was averaged to represent the stiffness after contraction $\left(\mathrm{G}^{\mathrm{KCl}}\right)$. (B) Contractility, quantified as the ratio of $\mathrm{G}^{\mathrm{KCl}}$ to $\mathrm{G} 0$, of the cells on substrates with stiffness of $1 \mathrm{kPa}, 10 \mathrm{kPa}$ and $50 \mathrm{kPa}$. Data shown are the means \pm standard deviation (SD). Statistical significance was analyzed using one-way ANOVA vs. the control, ${ }^{\prime} \mathrm{P}<0.05, \mathrm{n}=6$.

Effect of substrate stiffness on cell stiffness and contractile response. To investigate the effect of substrate stiffness on the mechanical properties of differentiated myofibroblasts, stiffness $\left(G^{\prime}\right)$ was measured using OMTC for TGF- $\beta 1$-induced cells grown on substrates with varying stiffness $(1,10$ and $50 \mathrm{kPa})$. In all cases, the cells exhibited typical power-law behavior whereby $\mathrm{G}^{\prime}$ increased weakly with frequency (f) and followed a power-law, $\mathrm{f}^{\alpha}$, where $\alpha$ was the slope of the power-law regression, as shown in Fig. 6. Furthermore, with the increase of substrate stiffness, the cell stiffness was also increased. The power-law exponent $\alpha$ increased from 0.108 to 0.122 as substrate stiffness increased.

To evaluate the effect of substrate stiffness on TGF- $\beta 1$-induced myofibroblast contractility, the contractile agonist, $\mathrm{KCl}(80 \mathrm{mM})$, was used to stimulate the cells. As shown in Fig. 7A, prior to $\mathrm{KCl}$ administration the cell stiffness fluctuated around a certain baseline level. Following administration of $\mathrm{KCl}$ to the cells at $60 \mathrm{sec}$, a rapid rise in cell stiffness was observed. The contractile response, or contractility of myofibroblasts to $\mathrm{KCl}$ stimulation was quantified as the ratio of the cell stiffness following $\mathrm{KCl}$ activation $\left(\mathrm{G}^{\mathrm{KCl}}\right)$ to baseline stiffness prior to $\mathrm{KCl}$ activation $(\mathrm{G} 0)$, i.e., $\mathrm{G}^{\mathrm{KCl}} / \mathrm{G} 0$. The plateau stiffness following $\mathrm{KCl}$ administration was averaged to represent the stiffness after contraction, as indicated by the box-window in Fig. 7A. Thus, with the increase of substrate stiffness, the reaction of cell contraction was increased. In contrast to the increased stiffness on $1 \mathrm{kPa}$ substrate, the cell stiffness on 10 and $50 \mathrm{kPa}$ substrates increased to 1.03 and $1.08(\mathrm{P}<0.05)$, respectively, as shown in Fig. 7B.

\section{Discussion}

Asthma is characterized by an increase in myofibroblast numbers and smooth muscle mass. Myofibroblasts have intermediate features between fibroblasts and smooth muscle cells (30) and they have been suggested to potentially act as precursors for smooth muscle cells. Mature myofibroblasts are able to serve multiple biological functions including contraction, proliferation, synthesis of extracellular matrix (ECM) proteins and the release of cytokines, chemokines, and growth factors. Accordingly, myofibroblasts are likely to be involved in the biological mechanism-driving progression of airway remodeling.

Hyperplasia of myofibroblasts is one of several structural changes that occur in airway remodeling. $\alpha$-SMA has been considered a myofibroblast marker protein, which is also a specific contractile phenotype marker. In this study, with substrate stiffness increase, the expression of $\alpha$-SMA mRNA (Fig. 3C) and protein (Fig. 5) of TGF- $\beta 1$-induced myofibroblasts were increased. It indicated that the differentiation of fibroblasts into myofibroblasts was increased with the increase of substrate stiffness. In addition, increased numbers of myofibroblasts were found in the airways of asthmatic patients, while their number appeared to correlate with the size of the basement reticular membrane (31). The results of our experiment were consistent with the set of in vitro experiments (31).

Myofibroblasts may contribute to tissue remodeling by releasing ECM components, such as elastin, fibronectin and collagen I. In this experiment, with substrate stiffness increase, the expression of collagen I mRNA (Fig. 3D) and the secretion of collagen I protein (Fig. 4) were stimulated, demonstrating that the airway remodeling was worsening.

In the present study, an OMTC method was used to determine the changing of the mechanical properties of the cells. During detection, the magnetic beads were linked to the cytoskeleton (F-actin) by the combination of RGD peptide with integrin receptor on the cell surface. Consequently, the detected stiffness of cells reflected the expression of F-actin. The study demonstrated that altering the stiffness of the underlying substrate under conditions that maintain a constant chemical environment may lead to the changing of cell stiffness. With the increase of 
substrate stiffness, the cell stiffness was also increased, i.e., the expression of the cytoskeleton (F-actin) was also increased.

The response of the cell contraction increased with substrate stiffness increase from 1 to $50 \mathrm{kPa}$ in the presence of TGF- $\beta 1$, as shown in Fig. 7. On the substrates with stiffness of $1 \mathrm{kPa}$, there was no contraction of cells essentially. However, on the substrates with stiffness of 10 and $50 \mathrm{kPa}$, the cell contraction was increased with the increase of substrate stiffness. It indicated that on stiffer substrates the expression of $\alpha$-SMA was higher, which was corresponding to the results in Fig. 5.

When the stiffness of ECM is increased, the fibroblasts need to form larger focal adhesions (FAs) to attach to the ECM to balance the increasing intracellular stress and mechanically resistant substrate. However, establishment of supermature FAs depends on two aspects: one is the high intracellular contractile activity generated by $\alpha$-SMA, the other is a stressresistant ECM (32). Thus, with ECM stiffness increase, the differentiation of fibroblasts into myofibroblasts in the presence of TGF- $\beta 1$ was also increased. This way, the expression of $\alpha$-SMA and F-actin are upregulated, leading to the high intracellular contractile activity and a more stress-resistant ECM.

In conclusion, The TGF- $\beta 1$-induced differentiation of fibroblasts into myofibroblasts was effected by substrate stiffness. The differentiation was stimulated when the substrate stiffness was increased. Hence, in an asthmatic airway, the ECM is markedly stiffer, which might induce the differentiation of airway fibroblasts to myofibroblasts. However, the increased myofibroblasts result in excessive synthesis and secretion of ECM proteins, such as collagen I, thus further thickening and stiffening the basement membrane. The process is a vicious circle. This finding may help better understand the underlying mechanisms of hyperplasia of airway myofibroblasts in asthma, which is likely to support more effective pathways for the therapy of asthma.

\section{Acknowledgements}

This study is partially supported by grants from the National Natural Science Foundation of China (grant no. 11172340), Chongqing Natural Science Foundation (grant no. CSTC2010BA5001), Training Program for Hundreds of Distinguished Leading Scientists of Chongqing and Sharing Fund of Chongqing University's Large-Scale Equipment (grant no. 2010063057, 2011063048, 2011063049).

\section{References}

1. Elias JA: Airway remodeling in asthma. Unanswered questions Am J Respir Crit Care Med 161: S168-S171, 2000.

2. Al-Muhsen S, Johnson JR and Hamid Q: Remodeling in asthma. J Allergy Clin Immunol 128: 451-464, 2011.

3. Sumi Y and Hamid Q: Airway remodeling in asthma. Allergol Int 56: 341-348, 2007.

4. Grainge CL, Lau LC, Ward JA, et al: Effect of bronchoconstriction on airway remodeling in asthma. N Engl J Med 364 2006-2015, 2011.

5. Jones RC and Jacobson M: Angiogenesis in the hypertensive lung: response to ambient oxygen tension. Cell Tissue Res 300: 263-284, 2000.

6. Serini G and Gabbiani G: Mechanisms of myofibroblast activity and phenotypic modulation. Exp Cell Res 250: 273-283, 1999.

7. Desmouliere A, Geinoz A, Gabbiani F and Gabbiani G: Trans forming growth factor-beta 1 induces alpha-smooth muscle actin expression in granulation tissue myofibroblasts and in quiescent and growing cultured fibroblasts. J Cell Biol 122: 103-111, 1993.
8. Evans RA, Tian YC, Steadman R and Phillips AO: TGF-beta1mediated fibroblast-myofibroblast terminal differentiation-the role of Smad proteins. Exp Cell Res 282: 90-100, 2003.

9. George SJ: Regulation of myofibroblast differentiation by convergence of the Wnt and TGF-beta1/Smad signaling pathways. J Mol Cell Cardiol 46: 610-611, 2009.

10. Halwani R, Al-Muhsen S, Al-Jahdali H and Hamid Q: Role of transforming growth factor- $\beta$ in airway remodeling in asthma. Am J Respir Cell Mol Biol 44: 127-133, 2011.

11. Brewster CE, Howarth PH, Djukanovic R, Wilson J, Holgate ST and Roche WR: Myofibroblasts and subepithelial fibrosis in bronchial asthma. Am J Respir Cell Mol Biol 3: 507-511, 1990.

12. Descalzi D, Folli C, Scordamaglia F, Riccio AM, Gamalero C and Canonica GW: Importance of fibroblasts-myofibroblasts in asthma-induced airway remodeling. Recent Pat Inflamm Allergy Drug Discov 1: 237-241, 2007.

13. Chicurel ME, Singer RH, Meyer CJ and Ingber DE: Integrin binding and mechanical tension induce movement of mRNA and ribosomes to focal adhesions. Nature 392: 730-733, 1998.

14. Shebanova O and Hammer DA: Biochemical and mechanical extracellular matrix properties dictate mammary epithelial cell motility and assembly. Biotechnol J 7: 397-408, 2012.

15. Huang $S$ and Ingber DE: The structural and mechanical complexity of cell-growth control. Nat Cell Biol 1: E131-E138, 1999.

16. Olsen AL, Bloomer SA, Chan EP, et al: Hepatic stellate cells require a stiff environment for myofibroblastic differentiation. Am J Physiol Gastrointest Liver Physiol 301: G110-G118, 2011.

17. Edwards DA, Gooch KJ, Zhang I, McKinley GH and Langer R: The nucleation of receptor-mediated endocytosis. Proc Natl Acad Sci USA 93: 1786-1791, 1996.

18. Sieminski AL, Padera RF, Blunk T and Gooch KJ: Systemic delivery of human growth hormone using genetically modified tissue-engineered microvascular networks: Prolonged delivery and endothelial survival with inclusion of nonendothelial cells Tissue Eng 8: 1057-1069, 2002.

19. Discher DE, Janmey P and Wang YL: Tissue cells feel and respond to the stiffness of their substrate. Science 310: 1139-1143, 2005.

20. Peyton SR, Ghajar CM, Khatiwala CB and Putnam AJ: The emergence of ECM mechanics and cytoskeletal tension as important regulators of cell function. Cell Biochem Biophys 47: 300-320, 2007.

21. Engler AJ, Sen S, Sweeney HL and Discher DE: Matrix elasticity directs stem cell lineage specification. Cell 126: 677-689, 2006.

22. Allen JL, Cooke ME and Alliston T: ECM stiffness primes the TGF $\beta$ pathway to promote chondrocyte differentiation. Mol Biol Cell 23: 3731-3742, 2012.

23. Toworfe GK, Composto RJ, Adams CS, Shapiro IM and Ducheyne P: Fibronectin adsorption on surface-activated poly(dimethylsiloxane) and its effect on cellular function. J Biomed Mater Res A 71: 449-461, 2004

24. Yim EK, Reano RM, Pang SW, Yee AF, Chen CS and Leong KW: Nanopattern-induced changes in morphology and motility of smooth muscle cells. Biomaterials 26: 5405-5413, 2005.

25. Goffin JM, Pittet P, Csucs G, Lussi JW, Meister JJ and Hinz B: Focal adhesion size controls tension-dependent recruitment of alpha-smooth muscle actin to stress fibers. J Cell Biol 172: 259-268, 2006.

26. Fuard D, Tzvetkova-Chevolleau T, Decossas S, Tracqui P and Schiavone P: Optimization of poly-di-methyl-siloxane (PDMS) substrates for studying cellular adhesion and motility. Microelectron Eng 85: 1289-1293, 2008.

27. Richter A, Puddicombe SM, Lordan JL, et al: The contribution of interleukin (IL)-4 and IL-13 to the epithelial-mesenchymal trophic unit in asthma. Am J Respir Cell Mol Biol 25: 385-391, 2001.

28. Fabry B, Maksym GN, Butler JP, Glogauer M, Navajas D and Fredberg JJ: Scaling the microrheology of living cells. Phys Rev Lett 87: 148102, 2001

29. Sniadecki NJ, Desai RA, Ruiz SA and Chen CS: Nanotechnology for cell-substrate interactions. Ann Biomed Eng 34: 59-74, 2006.

30. Roy SG, Nozaki Y and Phan SH: Regulation of alpha-smooth muscle actin gene expression in myofibroblast differentiation from rat lung fibroblasts. Int J Biochem Cell Biol 33: 723-734, 2001.

31. Holgate ST, Davies DE, Lackie PM, Wilson SJ, Puddicombe SM and Lordan JL: Epithelial-mesenchymal interactions in the pathogenesis of asthma. J Allergy Clin Immunol 105: 193-204, 2000.

32. Hinz B: Masters and servants of the force: The role of matrix adhesions in myofibroblast force perception and transmission. Eur J Cell Biol 85: 175-181, 2006. 